\title{
CONFERENCE OF COMMONWEALTH SURVEY OFFICERS
}

$\mathrm{T}$ 'HE Commonwealth Survey Officers' Conference was held in London and Cambridge during August 15-26. It was opened by Lord Lloyd, UnderSecretary of State for the Colonies, in the Department of Geography at Cambridge, and was attended by about two hundred representatives of Home and Commonwealth surveying departments and allied interests, including the directors of survey or surveyors-general of nearly all the Commonwealth territories, with observers from the United States of America, France, Holland, Belgium, Ireland and the Sudan. Between August 15 and 23, twonty-six papers were read on a wide variety of technical and administrative subjects, after which the Conference moved to London for visits to neighbouring government survey establishments. Brigadier M. Hotine, director of Colonial surveys, was president of the Conference. Delegates were mostly accommodated in Pembroke and Downing Colleges, a very convenient arrangement. A valuable adjunct was an exhibition of surveying instruments by eighteen British manufacturers.

Of the papers read, eight dealt with administration, education and land registration; three with the design of new instruments; eight with the routine of field surveying, nearly all from the point of view of air survey; three with the geodetic framework; one with variations of sea-level; and three with electronic aids to surveying. The list of titles might suggest that an aircraft and a box-full of electronics is now a good substitute for hard work on the ground ; but in one of the discussions it was well agreed that in most circumstancos the best map could still only be made by a fairly equal combination of both processes. The following notes give a short summary of the papers most likely to be of interest to readers of Nature.

In a paper on the use of automatic plotting machines for 1/1,250 air survey, Major D. V. Hutchinson described the combination of air and ground survey now being used for the city survey of Oxford, which will probably serve as a model for similar plans throughout Great Britain. The air-photo plotting machine requires less dense ground control than the old method of chain survey on the ground, but does not, of course, provide a map which can be accepted without ground verification and amplification. Clear diagrams of a sample plan show the amount of detail (about half) which is confidently identified on the photograph and plotted by the machine, and how much is left to be verified and amplified by the ground surveyor : at this scale, buildings with overhanging eaves come into the latter category. The out-turn of the ground surveyor has been increased from 0.28 sq. $\mathrm{km}$. a month without preliminary air survey to $0.48 \mathrm{sq}$. $\mathrm{km}$. with it. Total costs, including that of flying, are substantially lower than when ground survey alone is employed.

Prof. E. H. Thompson's new air-photo automatic plotting machine, of which the first model has just been completed by Messrs. Hilger and Watts, was on view and was the subject of a paper.

A paper by Major I. E. Sleep analysed the accuracy of a $1: 25,000$ map made by multiplex equipment from $1 / 90,000$ vertical photography, supplemented by $1 / 30,000$ obliques, taken from an aircraft at $45,000 \mathrm{ft}$., an altitude at which flying may be convenient in time of war. With ground control-points about 11 miles apart, errors of height were found to average $16 \mathrm{ft}$. and of position 12 metres, a standard which is adequate for a military $1 / 25,000$ map with 20-metre contours, and which is indeed remarkable considering the scale of photography and scarcity of control. A typical 1/25,000 map shet made in this way accompanies the paper, with the Ordnance Survey version (errorless in plan, but not in contouring) printed in grey, and the air-survey version in brown.

Surveyors will be interested to learn from a paper by $\mathrm{E}$. W. Taylor that the designers of the new small Tavistock theodolite have changed over to the coincidence system of reading, and that both circles are now read in a single eyepiece alongside the main telescope. In the geodetic model, a similar coincidence system is also being adopted; but the separate micrometers and eyepieces for the horizontal and vertical oircles are retained.

Commander W. I. Farquharson read a paper containing interesting descriptions of tidal bores, seiches, surges and secular changes of sea-level. From British tidal records, which are regrettably scanty, he has analysed the secular rises of sea-level during 1835$95,1895-1925$ and $1925-50$, and finds them to be zero, $0.4 \mathrm{ft}$. per century and $0.5 \mathrm{ft}$. per century, respectively. $\mathrm{He}$ quotes rises of 0.4 and $1.2 \mathrm{ft}$. per century for the two later periods from American records at Halifax, New York and Baltimore, and a similar value from Holland. He suggests that port engineers should be prepared for a further rise of $1 \mathrm{ft}$. during the coming century.

Capt. C. C. Lowry's paper on radio aids to hydrographic surveying described the usos and limitations of radio distance, depth and direction measuring apparatus as applied to hydrographic survey, and a paper by C. Powell gave details of the construction, use and accuracy of the Decca equipment.

A paper by D. L. Mills, of the United States Army Map Service, described the completion of the African Arc of the 30th meridian. This great piece of geodetic triangulation, which was begun about seventy years ago, has been finally completed since 1952 by a party from the U.S. Army Map Service observing the section between latitudes $1^{\circ}$ and $10^{\circ}$ north. This section includes 300 miles of the flat Sudd region, where triangulation is difficult and has only been mado possible by using $100-\mathrm{ft}$. portable Bilby steel towers. Three base-lines were measured by the Sudan Survey Department, and Laplace azimuth stations were observed at appropriate intervals.

One paragraph in this report answers a question which has often troubled surveyors, namely, what happens when a Bilby tower collapses. One such accident occurred, a tower collapsing with five men at the 100-ft. level. One broke a bone in his foot and the others were at work again after a day's rest. The ground was hard-baked clay. The Sudanese are evidently resilient.

The completion of the African arc, coupled with the radar connexion recently observed between Crete and Egypt, makes it possible (if desired) to compute 
South African triangulation in terms of the European Datum. Russian triangulation, known to exist but not published, could carry the same datum to Vladivostok, and a gap of 1,000 miles in Persia is all that prevents it extending to Singapore. Radar measures, of geodetic accuracy, between Europe, Greenland and America will link the European and American datums within a fow years, and triangulation from the latter already extends well into South America. The days of separate, isolated national surveys are passing.

A paper by H. A. Stamers Smith gave a useful summary of the present state of geodetic triangulation in Nigeria, where primary traverse has in places been very successfully used as a substitute for triangulation. The misclosures of ten such traverses are given, averaging about 1 in 100,000 in distances of 100-200 miles.

A paper by Col. R. C. A. Edge described work done by the Ordnance Survey with eloctronic computing. Traverse and levelling computations are a heavy item in the ordinary work, but, varying much in detail, require a high proportion of 'arranging' for pure computation. They are therefore more suited to punch-card mothods using a small calculator (such as the I.B.M. 626) than to a large storage computer. An I.B.M. 626 has recently been installed at the Ordnance Survey. Photogrammetric computations, another heavy item, are more uniform but mathematically more complex. They are suitable for a large computer, and for some time they have been programmed for, and successfully computed by, $A C E$. They are now being programmed for $D E U C E$.

Space does not admit mention of the remaining papers, but all are of value in their own spheres. These Survey Conferences are held at four-yearly intervals, and provide a most welcome opportunity for surveyors from all over the Commonwealth to exchange ideas and to renew friendships. The papers presented at previous conferences, and the resulting discussions, have been published by H.M. Stationery Office, and it is hoped that a 1955 volume will soon be published also.

G. BOMTORD

\section{INTERNATIONAL BIOMETRIC SYMPOSIUM IN BRAZIL}

$\mathrm{T}$

HE Biometric Society, which now forms the Biometric Section of the International Union of Biological Sciences, is endeavouring to stimulate the teaching and use of good statistical practices in biology in many parts of the world. As part of this programme, an international biometric symposium was held in Campinas, Brazil, during July 4-9. The University of São Paulo was host to the symposium, and a committee of the University Seminario de Estatistica, with Dr. C. G. Fraga (Institute of Agronomy, Campinas) as secretary, handled local arrangements; financial assistance was received from ten different governmental and non-governmental organizations. The ninety-eight statisticians and biologists attending included sixty-two from Brazil, eight from other Latin American countries, fourteen from the United States, five from Great Britain, seven from other European countries, and two from Asia. The foreign visitors will long remember the hospitality of their Brazilian hosts.
The president of the Society, Prof. W. G. Cochran (Johns Hopkins University), took as the subject of his address the 1954 trial of the Salk poliomyelitis vaccine in the United States, focusing attention on the design of the investigation rather than upon the outcome. He said that in 'placebo areas' children who received the vaccine were matched by controls receiving a similar injection of a placebo, while in other parts of the country the only controls were younger and older uninoculated children. The difference between case-rates in inoculated and control children was apparently greater in the placebo areas. His suggested explanation was that natural immunity was lower in the homes of children whose parents consented to their inclusion in the trial, a consent necessary in the placebo areas for all participators but elsewhere only for the inoculated.

In the afternoon, Sir Ronald Fisher (University of Cambridge) described the contribution of biometry to plant improvement, with special reference to experimental design, the analysis of genetic models involving large numbers of Mendelian factors that cannot be individually identified, and classical Mendelian genetics. Prof. E. R. Dempster (University of California) then discussed genetic models in animal breeding. Shorter papers on biometrical genetics by Prof. F. G. Brieger (Agricultural College, Piracicaba) and Dr. H. Kalmus (University College, London) related to autogamic populations and heterotic genes in plant geneties and to cyclomorphosis, respectively.

Two sessions on experimental design were held on July 5. Dr. S. C. Pearce (East Malling Research Station) showed that difficulties of adequate replication with perennial crops restrict the experimenter to very simple designs. A compensation is that relation. ships between many concomitant measurements can be studied. He illustrated the balancing of treatments so that one set of trees can be used for two or more consecutive investigations. E. Amaral (Institute of Agronomy, Pelotas) discussed missing yields and other problems in the analysis of sugarcane experiments. The design and analysis of coffee experiments at the Campinas Institute of Agronomy were reviewed by Dr. A. Conagin and Dr. Fraga, who showed how modern design had improved the quality of information obtainable in research on this crop. In a more theoretical paper, Dr. F. Pimentel Gomes (University of São Paulo) spoke of the use of the Mitscherlich equation in analysing fertilizer experiments on sugar-cane. In the afternoon, Miss G. M. Cox (University of North Carolina) surveyed recent work in the theory of experimental design; her paper was of particular interest for its mention of special designs for estimating optimal conditions, including the new category of rotatable designs. Dr. W. J. Youden (Bureau of Standards, Washington, D.C.) then gave a graphic account of how types of design developed by biologists are now assisting research on physical problems. With remarkable clarity and humour, he illustrated the adaptation of designs to situations in which the block size is predetermined; or, at most, two replications are wanted; or some treatments are to be chosen after part of the experiment was complete; or in which instrumental drift is a serious factor. On the follow. ing day, during a visit to the Agricultural College at Piracicaba, nembers held a discussion on experimental design for perennial crops. 